\title{
Erkek Öğrenci Gözüyle Toplumsal Cinsiyet: Bir Üniversite Örneği
}

\author{
Gender With the Eyes of Male Students: A Case of A University Summary
}

Filiz ADANA ${ }^{1}$, , Safiye ÖZVURMAZ ${ }^{1}$, Ayten TAŞPINAR $^{3}{ }^{\bullet}$

\author{
${ }^{1}$ Aydın Adnan Menderes Üniversitesi Hemşirelik Fakültesi Halk Sağlığı Hemşireliği Anabilim Dalı, Aydın, Türkiye \\ ${ }^{2}$ Aydın Adnan Menderes Üniversitesi Sağlık Bilimleri Fakültesi Ebelik Bölümü, Aydın, Türkiye
}

ÖZ

\begin{abstract}
Amaç: Doğumdan itibaren roller kadın ve erkeğin yaşamını biçimlendirir, tarihsel süreç içinde değişim gösterebilir ya da kültürler arasında farklılıklar olabilir. Toplumsal cinsiyet farklılığı bu anlamda herhangi bir farklılıktan çok daha derin anlamlar kazanır. Bu çalışma erkek üniversite öğrencilerinin toplumsal cinsiyet algılarının değerlendirilmesini amaçlamaktadır.

Yöntem: Çalışma kesitsel tipte bir araştırmadır. Araştırmanın örneklemini Aydın ilinde bir erkek yurdunda barınmakta olan 267 öğrenci oluşturmuştur. Çalışmanın verileri anket formu ve toplumsal cinsiyet algısı ölçeği ile toplanmıştır. Araştırmaya katılma kriterleri üniversite öğrencisi olmak, erkek olmak ve araştırmaya katılmaya gönüllü olmak olarak belirlenmiştir. Araştırmanın bağımsız değişkenleri kişisel bilgiler, bağımlı değişkeni Toplumsal Cinsiyet Algısı Ölçeği puanıdır. Çalışmaya katılan öğrencilerin yaş ortalamas 19.98 \pm 2.55 olup; \%52.1'inin ekonomik durumu orta düzeyde, \%71.9'unun aile tipi çekirdek aile; \%72.7'sinin annesi ve \%49.4'ünün babası ilkokul ve altı eğitim düzeyine sahiptir. Öğrencilerin \%88.8'inin annesi çalışmamakta, \%74.2'sinin babası çalışmaktadır. Çalışmamızda ölçeğin Cronbach's Alpha değeri 0.908 olarak bulunmuştur. Verilerin değerlendirilmesinde; tanımlayıcı istatistiksel analizler, İki Örnekli T test, Anova, Kruskal Wallis testleri kullanılmıștır.

Bulgular: Öğrencilerin Toplumsal Cinsiyet Algısı Ölçeği Puanları ortalaması 89.04 \pm 16.67 'dir. Çalışmamızda çekirdek ve tek ebeveynli aileye sahip olan, annesi çalışan öğrencilerin Toplumsal Cinsiyet Algısı Ölçeği Puanları ortalaması yüksek bulunmuştur. Sınıf, ekonomik durum, anne ve baba eğitim, baba çalışma durumu ile Toplumsal Cinsiyet Algısı Ölçeği Puanları arasında anlamlı fark bulunmamıştır. Öğrencilerin yaşları ile Toplumsal Cinsiyet Algısı Ölçeği Puanları arasında bir ilişki saptanmamıştır.

Sonuç: Çalışmamızda çekirdek ve tek ebeveynli aileye sahip olan, annesi çalışan öğrencilerin toplumsal cinsiyet algılarının daha olumlu olduğu bulunmuştur. Bu sonuçlar doğrultusunda geniş aileye sahip olan ve annesi çalışmayan erkek öğrencilerin toplumsal cinsiyet algısı açısından ele alınması önerilebilir.
\end{abstract}

Anahtar Kelimeler: Erkek, Öğrenci, Cinsiyet.

ABSTRACT

Objective: Roles can shape the life of men and women, change with in the historical process, or differ between cultures from birth. Gender difference becomes much deeper in this sense than any difference. This study aims to evaluate the gender perceptions of male university students.

Methods: This is an cross-sectional study. The sample of the study consisted of 267 students in a male dormitory in Aydın. Data were collected by questionnaire form and Gender Perception Scale. The criteria for participation in the study were determined as being a university student, being a man and volunteering to participate in the research. The independent variables of the study are personal in formation, dependent variable is Gender Perception Scalescore. The meanage of the students are $19.98 \pm 2.55$. The economic statusis medium level $52.1 \%$ and the family type is nuclear family $71.9 \%$. The mother of $72.7 \%$ and the father of $49.4 \%$ have primary and lower education level. In the study, In the study, the mother of $88.8 \%$ does not work and the student's father of $74.2 \%$ works. In our study, the Cronbach's Alpha value of the scale was found to be 0.908 . In the evaluation of the data; descriptive statistical analysis, Student-t test, Anova, Kruskal Wallis tests were used.

Results: The averages core of the Gender Perception Scaleis $89.04 \pm 16.67$. In our study, the mean score of the Gender Perception Scale of the students whose mother was working, having nuclear family and a single-parent family was found to be

Sorumlu Yazar: Filiz ADANA

Adnan Menderes Üniversitesi Hemşirelik Fakültesi Halk Sağlığı Hemşireliği Anabilim Dalı Aydın, Türkiye

filizadana@yahoo.com

Geliș Tarihi: 28.02.2019 - Kabul Tarihi: 06.04.2020 
high. No significant difference was found between the scores of class, economic situation, education of parents, father working status and Gender Perception Scale. There was no relationship between the ages of the students and the gender perception scales cores.

Conclusion: In study, the gender perception of the students whose mother was working, having a nuclear family and singleparent family was found to be high was found to be more positive. Based on these results, it can be suggested that male students who have large families and whose mothers do not work can be considered in terms of gender perception.

Key words: Male, Student, Gender.

\section{GíRíş}

İnsanlar kadın ya da erkek olarak dünyaya gelirler ve cinsiyetlerine göre toplumlarda kültürden kültüre değişen, sosyal olarak belirlenen çeşitli rollere sahip olurlar. Kadın ve erkek olarak toplumun bireyleri algılayış biçimi onların toplumsal cinsiyet rollerini belirler. Yani toplumsal cinsiyet rolü; kadın ve erkekle ilişkili olduğu kabul edilen rollerdir. Bireyler, toplum içinde rollerini sergilerken toplumsal yargılara da ayak uydururlar $(1,2)$.

Firsatların, kaynakların kullanımında, hizmetleri elde etmede bireyin cinsiyetinden dolayı ayrımcılığa uğramasına cinsiyet ayrımcılığ 1 denir. Cinsiyete dayanan ayrımcılık ailede başlamaktadır. Toplumların kadınlara biçtiği rol ve sorumluluklar onların eğitim, evlilik ve çalışma yaşamlarını birebir etkilemektedir. Pek çok toplumda kadın kültürel açıdan daha az değerli olarak nitelendirilir. Alan yazında toplumsal cinsiyet eşitliğinin oluşturulmasında üç yaklaşımdan bahsedilmektedir. Bunlar kadın ve erkeklere eşit davranılması, pozitif ayrımcılık ve toplumsal cinsiyet eşitliğinin temel politikalarda yer almasının sağlanmasıdır $(1,2,3)$.

Toplumlarda kadınlar ve erkekler arasında sorumluluklar ve kazançlar dağıtılırken adalet ve hakkaniyetin olması önemlidir. Bu yapılırken kadın ve erkeklerin cinsiyetlerinden kaynaklanan farklı gereksinim ve güçleri de göz önünde bulundurulmalıdır. Toplumsal cinsiyet rolü çoğu zaman her iki cinsiyetin de sağlığı üzerinde olumsuz etkiye sahip olmaktadır $(4,5)$. Ataerkil toplumsal yapı cinsiyet ilişkilerinin getirdiği iş bölümü ve kadın erkek rollerinin ayrımında ve ayrıca kadının çalışma yaşamına katılımlarında en önemli belirleyicilerdendir (2).

Toplumsal cinsiyet eşitsizliği tarih boyunca sorun olmuş, eşitsizliğin olumsuz sonuçları büyük oranda kadınları etkilemiştir. Kaynakların paylaşımında cinsiyet, önemli bir etmendir. Toplumlarda liderler olarak erkekler benimsenmiş ve toplumsal kaynakların çoğu onlara yönlendirilmiştir. Toplumun daha düşük sosyoekonomik düzeylerindeki kadınlar bu durumdan daha fazla etkilenmiş olsalar da; aslında olumsuz sonuçlar her sosyoekonomik düzeydeki kadın üzerine etkilidir $(1,6)$.

Toplumsal cinsiyet eşitsizliği her iki cinsiyet arasındaki biyolojik farklılıkların toplumsal farklılıklara dönüşmesinden ve toplumların kadın ve erkeğe farklı roller tanımlamasından kaynaklanmıştır. En geleneksel anlamda toplumlar, kadınları bağımlı olmaya, başarı ve güçten uzaklaştırmaya çalışırken erkekleri de güç ve otorite sahibi olmaya, duygularını ifade etmekten kaçınmaya yöneltmektedir. Kadının geleneksel olarak; eş, anne, kız çocuk ve kız kardeş rollerine sahiptir. Ayrıca kadının bakım verici rolü de insanlık tarihi boyunca en önemli rollerinden biri olmuştur. Bireyler içinde bulundukları kültürde bir kadın ya da erkek olarak nasıl düşünmeleri ve davranmaları gerektiğini öğrenirler. Bireyler toplumun kendilerine belirlediği roller kapsamında kadın ya da erkek olmayı öğrenerek büyürler. Doğumdan itibaren bu roller kadın ve erkeğin yaşamını biçimlendirir, tarihsel süreç içinde değişim gösterebilir ya da kültürler arasında farklılıklar olabilir. Toplumsal cinsiyet farklılığ 
bu anlamda herhangi bir farklılıktan çok daha derin anlamlar kazanır. Esen ve ark. (2017) üniversite öğrencilerinde yaptıkları çalışmalarında erkek öğrencilerin toplumsal cinsiyet algılarına ilişkin daha geleneksel bir bakış açısına sahip olduklarını belirtmişlerdir (7). Ancak Seçgin ve Tural'da (2011) öğretmen adayları ile yaptıkları çalışmada toplumdaki kadın ve erkeğin üstünde geleneksel normlar, kültürel değerlerin hala etkisini sürdürmesi ile birlikte, bu normlarda bir değişmenin de olduğunu bildirmektedir (8).

Günümüzde, hem dünya ülkelerinde hem ülkemizde toplumsal rolleri nedeni ile, kadınlar eğitim ve ekonomik kaynaklardan erkekler kadar faydalanamamakta, toplumsal ve ekonomik anlamda yeterli statü elde edememektedirler. Bu algının nedenlerini irdelemek için toplumun önemli bir yapısını oluşturan üniversite öğrencilerinde özelliklede erkek öğrencilerde yapılan çalışmalar toplumun konuya ilişkin durumunu ortaya koymak açısından önem taşımaktadır.

$\mathrm{Bu}$ çalışma erkek üniversite öğrencilerinin toplumsal cinsiyet algılarının değerlendirilmesini amaçlamaktadır.

Araştırma Sorusu:

1. Öğrencilerin kişisel bilgileri ile Toplumsal Cinsiyet Algısı Ölçeği puanları arasında fark var midir?

\section{GEREÇ VE YÖNTEMLER}

Çalışma analitik/kesitsel tipte bir araştırmadır. Adnan Menderes Üniversitesinde 20182019 Güz eğitim-öğretim yılında 56.726 öğrenci öğrenim görmektedir. Çalışmanın yapıldığ erkek öğrenci yurdunda 760 öğrenci barınmakta ve araştırmanın evrenini oluşturmaktadır. Çalışmada örneklem G-power analizi ile etki boyu orta (0.25) alındığında \%95 güç \%80 güven aralığında 267 olarak belirlenmiştir $(9,10,11)$.

Anketler gözlem altında uygulanmış ve katılan bireylerin kimlikleri gizli tutulmuştur. Çalışmada kullanılan formlar; literatür taraması ve uzman görüşü sonucu hazırlanan anket formu (8 soru) ve Toplumsal Cinsiyet Algısı Ölçeği'nden oluşmaktadır (6,9,12-14). Araştırmaya katılma kriterleri Adnan Menderes Üniversitesi öğrencisi olmak, erkek olmak ve araştırmaya katılmaya gönüllü olmak olarak belirlenmiştir. Araştırmanın Bağımsız değişkenleri kişisel bilgiler, bağımlı değişkeni Toplumsal Cinsiyet Algısı Ölçeği puanıdır.

Toplumsal Cinsiyet Algısı Ölçeği (TCAÖ): Altınova ve Duyan (2013) tarafından bireylerin toplumsal cinsiyet algılarını ölçmek amacıyla geliştirilmiş olan ölçekte 25 madde bulunmaktadır. Beşli likert şeklindeki ölçekte olumsuz maddeler tersten hesaplanmaktadır. Ölçekte 2., 4., 6., 9., 10., 12., 15., 16., 17.,18., 19., 20., 21., 24. ve 25. maddeler olumsuzdur. Ölçekten alınabilecek minimum puan 25; maksimum125'tir ve yüksek puanlar toplumsal cinsiyet algısının olumlu olduğunu göstermektedir (15). Ölçeğin Cronbach's Alpha değeri 0.872 olup; bizim çalışmamızda ölçeğin Cronbach's Alpha değeri 0.908 olarak bulunmuştur.

Elde edilen veriler SPSS istatistik paket programında (Version 18, Chicago IL, USA) değerlendirilmiştir. Çalışmanın verileri normal dağılım analizi kapsamında; Gauss eğrisi, ortalama puan, minimum ve maksimum puan genişliği, Kolmogorov-Simirnov testi anlamlılık düzeyi açısından değerlendirilmiş; normal dağılım gösteren karşılaştırmalarda t testi, ANOVA; normal dağılım göstermeyen karşılaştırmalarda Kruskal Wallis $H$ test kullanılmıştır. Araştırmaya başlamadan önce gerekli izinler alınmıştır. 


\section{BULGULAR}

Çalışmaya katılan öğrencilerin yaş ortalaması 19.98 \pm 2.55 olup; \%34.1'i birinci sınıf, \%38.2'si ikinci sınıf, \%17.2'si üçüncü sınıf, \%10.5'i dördüncü sınıftır. Öğrencilerin \%52.1'inin ekonomik durumu orta düzeyde, \%71.9'unun aile tipi çekirdek aile; \%72.7'sinin annesi ve \%49.4'ünün babası ilkokul ve altı eğitim düzeyine sahiptir. Öğrencilerin \%88.8'inin annesi çalışmamakta, \%74.2'sinin babası çalışmaktadır. TCAÖ Puanları ortalaması 89.04 $\pm 16,67$ 'dir.

Çalışmamızda çekirdek ve tek ebeveynli aileye sahip olan öğrencilerin geniş ailelere sahip olanlara göre ve annesi çalışan öğrencilerin çalışmayanlara göre TCAÖ Puanları ortalaması yüksek bulunmuştur. Sınıf, ekonomik durum, anne ve baba eğitim, baba çalışma durumu ile TCAÖ Puanları arasında anlamlı fark bulunmamıştır (Tablo 1).

Tablo 1. Öğrencilerin kişisel özellikleri ile TCAÖ Puanlarının Karşılaştırılması

\begin{tabular}{|c|c|c|c|c|}
\hline $\begin{array}{l}\text { Kişisel } \\
\text { Özellikler/TCAÖ }\end{array}$ & Sayı & $\%$ & TCAÖ $(\mathrm{AO} \pm \mathrm{SS})$ & test, p \\
\hline \multicolumn{4}{|l|}{ Sinıf } & \multirow{5}{*}{$\begin{array}{c}* 2.177 \\
0.091\end{array}$} \\
\hline 1. Sinif & 91 & 34.1 & $92.18 \pm 16.32$ & \\
\hline 2. Sinif & 102 & 38.2 & $87.10 \pm 16.46$ & \\
\hline 3. Sinıf & 44 & 17.2 & $86.02 \pm 16.54$ & \\
\hline 4. Sinif & 30 & 10.5 & $90.85 \pm 17.77$ & \\
\hline \multicolumn{4}{|l|}{ Ekonomik Durum } & \multirow{4}{*}{$\begin{array}{c}* 1.897 \\
0.152\end{array}$} \\
\hline Kötü & 98 & 36.7 & $88.12 \pm 16.69$ & \\
\hline Orta & 139 & 52.1 & $90.66 \pm 16.28$ & \\
\hline İyi & 30 & 11.2 & $84.56 \pm 17.92$ & \\
\hline \multicolumn{4}{|l|}{ Aile Tipi } & \multirow{4}{*}{$\begin{array}{c}* * 14.225 \\
0.001\end{array}$} \\
\hline Çekirdek Aile & 192 & 71.9 & $\begin{array}{c}143.04 \text { (Median:92.5) } \\
(44-124)\end{array}$ & \\
\hline Geniş Aile & 58 & 21.7 & $\begin{array}{c}100.22 \text { (Median:80) } \\
(43-123)\end{array}$ & \\
\hline Tek ebeveynli Aile & 17 & 6.4 & $\begin{array}{c}147.09 \text { (Median:96) } \\
(69-125)\end{array}$ & \\
\hline \multicolumn{4}{|l|}{ Anne Ĕgitim } & \multirow{4}{*}{$\begin{array}{c}* 1.691 \\
0.186\end{array}$} \\
\hline İlkokul ve altı & 194 & 72.7 & $89.06 \pm 16.47$ & \\
\hline Ortaokul & 30 & 11.2 & $84.70 \pm 16.25$ & \\
\hline Lise ve üstü & 43 & 16.1 & $91.97 \pm 17.62$ & \\
\hline \multicolumn{4}{|l|}{ Baba Ĕgitim } & \multirow{4}{*}{$\begin{array}{c}* 2.419 \\
0.091\end{array}$} \\
\hline İlkokul ve altı & 132 & 49.4 & $90.83 \pm 16.42$ & \\
\hline Ortaokul & 49 & 18.4 & $84.75 \pm 17.10$ & \\
\hline Lise ve üstü & 86 & 32.2 & $88.74 \pm 16.54$ & \\
\hline \multicolumn{4}{|l|}{ Anne Çalışma } & \multirow{3}{*}{$\begin{array}{l}1.770 \\
0.013\end{array}$} \\
\hline Çalışıyor & 30 & 11.2 & $96.16 \pm 14.04$ & \\
\hline Çalışmıyor & 237 & 88.8 & $88.14 \pm 16.79$ & \\
\hline \multicolumn{4}{|l|}{ Baba Çalışma } & \multirow{3}{*}{$\begin{array}{c}* * * 2.706 \\
0.953\end{array}$} \\
\hline Çalışıyor & 198 & 74.2 & $89,08 \pm 17,10$ & \\
\hline Çalışmıyor & 69 & 25.8 & $88.94 \pm 15.50$ & \\
\hline Yaş & $\begin{array}{l}\mathrm{AO} \pm \mathrm{SS} \\
(\mathrm{Min}-\mathrm{Max})\end{array}$ & \multicolumn{2}{|c|}{$20.04 \pm 2.30(17-28)$} & \\
\hline TCAÖ Puanı & $\begin{array}{l}\mathrm{AO} \pm \mathrm{SS} \\
\text { (Min-Max) }\end{array}$ & \multicolumn{2}{|c|}{$89.04 \pm 16.67(43-125)$} & \\
\hline
\end{tabular}


Öğrencilerin yaşları ile TCAÖ Puanları arasında bir ilişki saptanmamıştır (Tablo 2).

Tablo 2. Öğrencilerin Yaşları ile TCAÖ Puanları İlişkisi

\begin{tabular}{lrrr}
\hline Yass/TCAP & Toplumsal Cinsiyet Algısı Puanları & \\
\hline Yaş $\quad \mathrm{r}$ & & ${ }_{-.031}$ \\
\hline $\mathrm{p}$ & .612 \\
\hline Pearson Correlation test & &
\end{tabular}

*Pearson Correlation test

\section{TARTIŞMA}

Toplumsal cinsiyet algısı bir toplumdan diğerine farklılık gösterebildiği gibi aynı toplumun içinde farklı sosyodemografik özelliklerden de etkilenebilir. Ülkemizde yapılan araştırmalar sonucunda ulaşılan bulgulara göre, erken ve orta çocukluk dönemi çocuklarının büyük bir kısmı anne kavramını bakım veren ve temizlik- yemek yapan kişi, baba kavramını ise erken çocukluk dönemindeki çocuklar işe giden, dördüncü sınıf çocukları ise bizi koruyan kişi eylemi ile belirtmişlerdir $(13,14,16,17)$. Algılanan cinsiyet rolleri gençlerin meslek seçimini, spor aktivitesini, yaşamının birçok alanını etkileyebilir (18). Bu nedenle hem toplumlar arası hem de toplum içi özelliklere dayalı araştırmalar yapmak cinsiyet algısının değişkenlerini belirlemek için önemli ve gereklidir.

Çalışmamızda öğrencilerin TCAP ortalaması 89.04 \pm 16.67 'dir. İlhan Dikmen ve Ak (2017) çalışmaları kapsamında ele aldıkları erkek öğrencilerde TCAÖ puanını 82.0 olarak bulmuşlar ve istendik düzeyde olmadığını ifade etmişlerdir (14). Bizim araştırmamızda toplumsal cinsiyetin algısının daha olumlu olduğu söylenebilir. Öğrencilerin toplumsal cinsiyet algılarının ortanın üzerinde bir düzeyde bulunmasının nedeninin çalışmanın Türkiye'nin batısındaki bir ilde ve üniversite öğrencilerinde yapılması olduğu düşünülmektedir.

Toplumlarda geleneksel yapı bireylere geleneksel cinsiyet rolleri çizmektedir. Ülkemizde de geniş aileler daha fazla geleneksel örüntüler taşımakta ve bu yapı erkek otoritesine dayanan geleneksel bir bakış açısı içermektedir. Daha çok ataerkil yapıda varlığını sürdüren geniş ailelerde daha katı toplumsal cinsiyet rollerine rastlanmakta bu durum tüm aile üyeleri tarafindan benimsenmektedir $(16,17)$.

Çalışmamızda çekirdek ve tek ebeveynli aileye sahip olan öğrencilerin geniş ailelere sahip olanlara göre ve annesi çalışan öğrencilerin çalışmayanlara göre TCAÖ Puanları ortalaması yüksek bulunmuştur.

Alanyazın çalışmalarında toplumsal cinsiyet algısının aile tipinden etkilendiğini gösteren çalışmalar mevcuttur $(11,19,20)$. Erzeybek'in (2015) çalışmasında çekirdek aile yapısındaki bireylerin toplumsal cinsiyet rollerinin ve algılarının daha olumlu ve eşitlikçi olduğu; Uçtu ve Karahan'ın (2016) çalışmalarında çekirdek aileye sahip olanların, geniş aileye sahip olanlara göre Cinsiyet Rolü Envanterinden daha yüksek puan aldıkları belirlenmiştir $(17,19)$. Alan yazın bulgularının aile tipi değişkeni açısından çalışma bulgularımızla paralellik göstermektedir. Çalışma bulgularımız ve alanyazın doğrultusunda toplumsal ve kültürel yapıyı daha fazla içinde barındıran ve daha geleneksel olan geniş aile yapısının toplumsal cinsiyet algısını olumsuz etkilediği söylenebilir.

Günümüzde kadınların çalışma yaşamına girdiği toplumlarda kadın ve erkek cinsiyetine ilişkin geleneksel roller kadınların lehine değişmeye başlamıştır (7). Attanpola (2004) kadınların çalışma yaşamına katılması ile birlikte kalıplaşmış toplumsal cinsiyet rollerinde bir 
gevşeme olduğunu ve zamanla cinsiyet rollerinde değişikliklerin oluştuğunu vurgulamıştır (21). Öngen'in (2013) üniversite öğrencileriyle Kantoğlu'nun (2017) annesi önceden çalışmış veya halen çalışmakta olan katılımcılarla yaptıkları çalışmalarda, anneleri çalışan öğrencilerin toplumsal cinsiyet rollerine ilişkin eşitlikçi rolleri benimsedikleri belirlenmiştir $(9,10)$. Benzer bir şekilde Varol ve ark. (2016) çalışmalarında annesi işsiz-ev emekçisi olan öğrencilerin Cinsiyet Eşitliği Ölçeği puanlarını düşük bulmuştur (22). Murray (2004) çalışmasında her iki ebeveyni de çalışan çocukların kadın ve erkeklere ilişkin daha az kalıp yargısal görüşleri olduğunu açıklamıştır (13).

Alan yazın bulgularının annenin çalışma durumu değişkeni açısından çalışma bulgularımızla paralellik göstermektedir. Çalışma bulgularımız ve alanyazın doğrultusunda annelerin çalışmamasının toplumsal ve kültürel örüntüleri daha fazla içinde barındıran ve daha geleneksel algıyı desteklediği ve toplumsal cinsiyet algısını olumsuz etkilediği söylenebilir. $\mathrm{Bu}$ bulgular doğrultusunda annesi çalışan çocukların daha olumlu cinsiyet algısına sahip oldukları görülmektedir.

Çalışmamızda sınıf, ekonomik durum, anne ve baba eğitim, baba çalışma durumu ile TCAÖ Puanları arasında anlamlı fark bulunmamıştır.

Kodan ve Çetinkaya (2013) üniversite öğrencileri ile yaptı̆̆ bir çalışmada ailenin ortalama aylık geliri, anne eğitim durumu, ile toplumsal cinsiyet rollerine ilişkin tutum puan ortalamaları arasında fark bulunmuştur (23). Varol ve ark. (2016) çalışmalarında Cinsiyet Eşitliği Ölçeği puanlarını anne ve baba eğitim düzeyi ile karşılaştırmış; eğitim düzeyi düşük olanların puanlarının daha düşük olduğunu ifade etmişlerdir (22). Kantoğlu ve ark. (2018) babaların çalışma durumu ile eşitlikçi cinsiyet rollerini karşılaştırmış; babaların çoğunluğunun çalışıyor olması nedeni ile bir sonuca ulaşamamıştır (9). Aynı çalışmada ekonomik düzeyin yükselmesi ile katılımcıları daha fazla eşitlikçi toplumsal cinsiyet rollerine sahip olunduğu sonucuna ulaşılmıştır. Çalışmamızda ilgili değişkenlerle toplumsal cinsiyet algısı arasında fark saptanamamasının nedeni araştırmanın tek bir cinsiyet grubu ve tek bir üniversite örnekleminde yapılmış olması olabilir.

Öğrencilerin Yaşları ile TCAÖ Puanları arasında bir ilişki saptanmamıştır. Özden ve Gölbaşı (2018) 35 yaş ve üzeri sağlık çalışanlarının, 34 ve altı yaş grubundan daha eşitlikçi bir toplumsal cinsiyet algısına sahip olduğunu bildirmişlerdir (24). Çalışmamızda yaş aralığı dar olduğundan (17-28) alanyazını destekleyici bir bulguya ulaşılmadığı düşünülmüştür.

Bu çalışma ile gençlerin önemli bir bölümünü oluşturan erkek üniversite öğrencilerinin toplumsal cinsiyete bakışı ve bu bakışa etkili etmenleri elde edilmiştir.

\section{SONUÇ VE ÖNERİLER}

Çalışmamızda çekirdek ve tek ebeveynli aileye sahip olan, annesi çalışan öğrencilerin toplumsal cinsiyet algılarının daha olumlu olduğu bulunmuştur. Bu sonuçlar doğrultusunda geniş aileye sahip olan ve annesi çalışmayan erkek öğrencilerin toplumsal cinsiyet algısı açısından ele alınması önerilebilir.

\section{Çalışmanın kısıtlılıkları}

Çalışma bulguları bir üniversitede okuyan erkek öğrencilerle, çalışmada kullanılan anket soruları ve istatistiksel yöntemlerle sinırlıdır. 


\section{KAYNAKLAR}

1. Doğan, H. Ö., \& Piyal, B. (2017). Toplumsal cinsiyetle ilişkili sorunlar. Turk J Public Health, 15(2), 150-163.

2. Özçatal., E. Ö. (2011). Ataerkillik, toplumsal cinsiyet ve kadının çalışma yaşamına katılımı. Çankırl Karatekin Üniversitesi İktisadi ve İdari Bilimler Fakültesi Dergisi, 1(1), 21-39.

3. Keuken. D., Bindels, P., Klazinga, N., \& Haafkens, J. (2012). A systematic approach for up take of evidence on sex-specificissues in guidelines-a pilot study. J Eval Clinical Pract, 18(2), 369-77.

4. Lee, D., \& Kashubeck-West, S. (2015). Factor structure of the Bem Sex Role Inventory in samples of ethnically diverse young adults in the US. Journal of Asia Pacific Counseling, 5(1), 1-22.

5. Kahraman, L., Kahraman, A. B., Ozansoy, N., Ak1llı, H., Kekillioğlu, A., \& Özcan, A. (2014). Nevşehir Hacı Bektaş Veli Üniversitesi toplumsal cinsiyet algısı araştırması. Turkish Studies, 9(2), 811-831.

6. Badura, K. L., Grijalva, E., Newman, D. A., Yan, T. T., \& Jeon, G. (2018). Gender and leader ship emergence: A meta-analysis and explanatory model. Personnel Psychology, 71, 335-367.

7. Esen, E., Siyez, D. M., Soylu, Y., \& Demirgürz, G. (2017). Üniversite öğrencilerinde toplumsal cinsiyet algısının toplumsal cinsiyet rolü ve cinsiyet değişkenlerine göre incelenmesi. E-Uluslararası Ĕ̈itim Araştırmaları Dergisi, 8(1), 46-63.

8. Seçgin, F., \& Tural, A. (2011). Sınıf öğretmenliği bölümü öğretmen adaylarının toplumsal cinsiyet rollerine ilişkin tutumları. e-Journal of New World Sciences Academy Education Sciences, 6(4), 2446-2458.

9. Kantoğlu, A., Çetin, N. Y., \& Erdoğan, A. (2018). Ergenlerde toplumsal cinsiyet algılarının sosyodemografik özelliklere göre değerlendirilmesi. Konuralp Tıp Dergisi, 10(2), 175-187.

10. Öngen, B., \& Aytaç, S. (2013). Üniversite öğrencilerinin toplumsal cinsiyet rollerine ilişkin tutumları ve yaşam değerleri ilişkisi. Sosyoloji Konferansları , 48(2013-2), 1-18.

11. Aylaz, R., Güneş, G., Uzun, Ö., \& Ünal, S. (2014). Üniversite öğrencilerinin toplumsal cinsiyet rolüne yönelik görüşleri. Sürekli Tip Eğitimi Dergisi, 23(5), 183-189.

12. Altuntaş, O., \& Altınova, H. H. (2015). Toplumsal cinsiyet algısı ile sosyo-ekonomik değişkenler arasındaki ilişkinin belirlenmesi. Turkish Studies-International Periodical for the Languages, Literature and History of Turkishor Turkic, 10(6), 83-100.

13. Güder, S. Y., \& Yıldız, T. G. (2016). Okul öncesi dönemdeki çocukların toplumsal cinsiyet algılarında ailenin rolü. Hacettepe Üniversitesi Ĕ̈itim Fakültesi Dergisi (H.U. Journal of Education), 31(2), 424-446.

14. İlhan, M. N., Dikmen, A. U., \& Ak, N. (2017). Toplumsal cinsiyet algisinin değerlendirilmesi. International Journal of Social And Humanities Sciences, 1(2), 108121.

15. Altınova, H. H., \& Duyan, V. (2013). Toplumsal cinsiyet algısı ölçeğinin geçerlik güvenirlik çalışması. Toplum ve Sosyal Hizmet, 24(2), 9-14.

16. Akar, T., \& Aksoy, A. B. (2018). Çocukların anne babalarına yönelik algılarının toplumsal cinsiyet bağlamında incelenmesi. Adnan Menderes Üniversitesi Ĕgitim Fakültesi Eğitim Bilimleri Dergisi, 9(1), 31-46.

17. Erzeybek, B. (2015). Anne-Babaların çocuklarını yetiştirirken benimsedikleri toplumsal cinsiyet rolleri tutumları. (Yayımlanmamış Yüksek Lisans Tezi). Ankara Üniversitesi Sağlık Bilimleri Enstitüsü, Ankara. 
18. Boiche, J., Chalabaev, A., \& Sarrazin, P. (2014). Evolution of gender sport stereo types during adolescence: A 3-wave longitudinal study. Psychology of Sportand Exercise, (15), 212-215.

19. Uçtu, A. K., \& Karahan, N. (2016). Sağlık yüksekokulu öğrencilerinin cinsiyet rolleri, toplumsal cinsiyet algısı ve şiddet eğilimleri arasındaki ilişkinin incelenmesi. Insan ve Toplum Bilimleri Araştırmaları Dergisi, 5(8), 2882-2905.

20. Angın, E., Yazıcı, Z., Orçan, Kaçan, A., Kanak, M., Yurtsever Kılıçgün, M., Oral, T., ve ark. (2015). Erken çocukluk döneminde gelişim, 1. Bask1, Ankara: Eğiten Kitap Yayıncilik, 173-193.

21. Attanapola, C. T. (2004). Changing gender roles and health impacts among female workers in export-processing industries in Sri Lanka. Socialand Medicine, 58, 23012312.

22. Varol, Z. S., Çiçeklioğlu, M., \& Taner, Ş. (2016). Bir tıp fakültesi birinci sınıf öğrencilerinde toplumsal cinsiyet algı düzeyi ve ilişkili faktörlerin değerlendirilmesi. Ege Tip Dergisi, 55(3):122-128.

23. Kodan Çetinkaya, S. (2013). Üniversite öğrencilerinin şiddet eğilimlerinin ve toplumsal cinsiyet rollerine ilişkin tutumlarının incelenmesi. Nesne, 1(2), 21-43.

24. Özden, S., \& Gölbaşı, Z. (2018). Sağlık çalışanlarının toplumsal cinsiyet rollerine ilişkin tutumlarının belirlenmesi. KOU Sag Bil Derg, 4(3), 95-100. 